\title{
Gestão ecológica das águas: uma comparação das diretrizes do Brasil e da Europa
}

\author{
Ecological water management: \\ a comparison between Brazilian and European guidelines
}

Gestión ecológica del agua:

una comparación de las pautas de Brasil y Europa ${ }^{1}$

Rafaela Silva de Faria ${ }^{2}$

Claudia Padovesi-Fonseca ${ }^{3}$

\begin{abstract}
Resumo
FARIA, R. S. de; PADOVESI-FONSECA, C. Gestão ecológica das águas: uma comparação das diretrizes do Brasil e da Europa. Rev. CઐTrópico, v. 44, n. 1, p. 101-117, 2020. DOI: https://doi. org/10.33148/cetropicov44n1(2020)art5
\end{abstract}

A política hídrica deve conter diretrizes compatíveis para uma gestão integrada da sociedade, e assumir a proteção das águas e seu uso sustentável. Neste artigo, traçamos paralelos de enquadramento das águas nas diretivas brasileira e europeia, além de agregar as diretrizes europeia em abastecimentos de água no Brasil. As políticas elencam a bacia hidrográfica como unidade de planejamento, e prevê o enquadramento das águas como instrumento de integração para usos humanos. No Brasil, as águas são classificadas de acordo com condições ambientais e associadas aos usos. Das especiais, quando não alteradas por atividades humanas; adequadas para abastecimento; e até somente usadas para navegação. A diretiva europeia tem como objetivo alcançar o bom estado ecológico para as águas. Destacam-se três aspectos nas configurações entre as diretivas brasileira e europeia. A diretiva europeia prevê metas progressivas para determinados períodos, que garante um acompanhamento efetivo do processo de avaliação e resposta. A comunidade é atuante nas diretrizes da gestão europeia, em contraste com a do Brasil, que é mais genérica. A diretiva europeia é mais ampla no âmbito da União Europeia. Há contrastes entre as realidades brasileira e europeia, com adaptações necessárias quando aplicadas aqui. O gerenciamento de recursos hídricos é complexo, cuja análise necessita de instrumentos técnicos robustos e ao mesmo tempo adaptáveis, que

\footnotetext{
Agradecemos à Coordenação de Aperfeiçoamento de Pessoal Nível Superior (CAPES), ao Programa de Mestrado Profissional em Rede Nacional em Gestão e Regulação de Recursos Hídricos ( ProfÁgua) Projeto CAPES/ ANA AUAXPE no 2717/2015 e à Fundação de Apoio à Pesquisa do Distrito Federal (FAPDF) - Edital 05/2018.

2 Bacharel em Engenharia Florestal pela Universidade Federal do Recôncavo da Bahia - UFRB, Cruz das Almas (BA); Mestranda em Gestão e Regulação de Recursos Hídricos - ProfÁgua na Universidade de Brasília - UnB, Planaltina (DF).rafaela_fariia@hotmail.com. Orcid: https://orcid.org/0000-0001-6160-5116.

3 Professora associada da Universidade de Brasília (UnB), Líder do Núcleo de Estudos Limnológicos (NEL)CNPq, Mestre e Doutora em área de Limnologia pela Universidade de São Paulo (USP), realizou Pós Doutorado na Universidade de Paris Pierre e Marie Curie, Paris, França e na Universidade de Granada, Granada, Espanha. padovesif@gmail.com. Orcid: https://orcid.org/0000-0001-7915-3496.
} 
devem seguir diretrizes de legislação ambiental, com produção de cenários consolidados para o enquadramento das águas. A Política das Águas brasileira apresenta medidas promissoras, com potencial alcance em preservação, mas muito deve ser feito na sua gestão hídrica.

Palavras-chave: Enquadramento das águas. Monitoramento ambiental. Gestão de reservatórios. Diretiva Quadro da Água Europeia.

\section{Abstract}

FARIA, R. S. de; PADOVESI-FONSECA, C. Ecological water management: a comparison between Brazilian and European guidelines. Rev. C\&Trópico, v. 44, n. 1, p. 101-117, 2020. DOI: https://doi. org/10.33148/cetropicov44n1(2020)art5

The water policy must be based on guidelines directed to society integrated management, and it assumes the water protection from the sustainable development perspective. This study aimed to draw parallels for water quality guidelines applied in Brazil and Europe, and further use of the European one here. The two water policies consider the watershed as a planning unit and provide the different use classes of waters a tool for the integrating system. Brazilian waters are classified according to environmental conditions and they are associated with uses. Special class refers to water not altered by human activities; an intermediate environmental condition is suitable for supply; and even only used for navigation. The objective of the European directive is to achieve good ecological status for water-bodies. Three aspects stand out in the configurations between Brazilian and European directives. The European proposes progressive targets for certain periods, which guarantees effective monitoring by evaluation and response process. There is effective participation of the community in the European guidelines, in contrast to Brazil, which is more generic. The integrative organizational structure of the European directive is more broadly with the European Union. There are contrasts between Brazilian and European realities, and adaptations are necessaries when applied in Brazil. Water management resources are complex, within analysis by viable and adapted technical instruments, which must follow environmental laws, with future scenarios for water classing. Water Policy in Brazil presents effective measures, which can achieve preservation, but much can still be done to improve its water resource management.

Keywords: Water framework. Environmental monitoring. Reservoir management. European Water Framework Directive.

\section{Resumen}

FARIA, R. S. de; PADOVESI-FONSECA, C. Gestión ecológica del agua: una comparación de las pautas de Brasil y Europa. Rev. CßTrópico, v. 44, n. 1, p. 101-117, 2020. DOI: https://doi. org/10.33148/cetropicov44n1(2020)art5

La gestión de los recursos hídricos supone pautas compatibles e integradas a la sociedad. Este artículo compara algunos aspectos de dos realidades distintas: la europea y la brasileña, enmarcando sus directivas y agregando las directrices europeas y el suministro de agua en Brasil. La cuenca hidrográfica es una 
unidad de planificación, según las políticas, y el enmarcado de las aguas es una herramienta de integración para los usos humanos. Brasil clasifica sus aguas según las condiciones ambientales y se asocian con los usos. Hay las que no sufren con las actividades humanas. Las de suministro. Las que se usan solo para la navegación. El objetivo de la directiva europea es lograr un buen estado ecológico para sus aguas. Subrayamos algunos aspectos de las directivas. En Europa hay objetivos progresivos para ciertos períodos, garantizando así un monitoreo efectivo del proceso de evaluación y respuesta. La comunidad es más activa en las directrices de gestión, contrastando con Brasil, que presenta una gestión más genérica. La directiva europea es más amplia dentro de la Unión Europea. Además de lo antes informado, hay otros contrastes y diferencias entre las realidades brasileña y europea. La gestión de los recursos hídricos es algo complejo y su análisis requiere instrumentos potentes y adaptables, que deben seguir las pautas de la legislación ambiental, con la producción de escenarios consolidados para el enmarcado de las aguas. La Política Brasileña del Agua presenta medidas prometedoras, con potencial para la preservación, pero queda mucho por hacer en su gestión del agua.

Palabras clave: Marco de agua. Monitoreo ambiental. Gestión de embalses. Directiva Marco del Agua Europea.

Data de submissão: 19/03/2020

Data de aceite: 08/06/2020

\section{Introdução}

A gestão dos recursos hídricos é um tema recorrente na atualidade, visto que a disponibilidade de água, sobretudo para fins como o abastecimento humano, tem sofrido reduções expressivas em função do comprometimento de seus aspectos de qualidade e quantidade.

Neste âmbito, uma boa gestão dos recursos hídricos necessita de políticas de planejamento adequadas e, consequentemente, de instrumentos que garantam a gestão sustentável e integrada em todos os setores que abrangem a proteção dos recursos compatível com o desenvolvimento da sociedade humana.

A Política Nacional de Recursos Hídricos - PNRH, instituída pela Lei Federal $n^{\circ} 9.433$, de 08 de janeiro de 1997, representa um marco na gestão dos recursos hídricos no Brasil. Elenca a bacia hidrográfica como unidade de planejamento e prevê o enquadramento dos corpos d'água como principal instrumento de integração da qualidade e quantidade de água. Este enquadramento deve ser parte do processo de planejamento descentralizado e de gestão participativa, e a água como um bem dotado de valor econômico (BRASIL, 1997).

A PNRH atribui o enquadramento dos corpos hídricos em classes com a finalidade de assegurar às águas qualidade compatível com os usos mais exigentes a que 
forem destinadas. Além disso, pretende diminuir os custos de combate à poluição das águas, mediante ações preventivas (BRASIL, op. cit.). O enquadramento indica o nível de classe da água a ser alcançado ou mantido ao longo do tempo.

Para que o enquadramento seja aplicado é necessário que se avaliem os usos, que são feitos e os que se pretende fazer, das águas na bacia hidrográfica na qual o corpo d'água está inserido e, posteriormente, executar políticas públicas para que as metas sejam alcançadas (CARDOSO-SILVA et al., 2015). No Brasil, a categorização dos corpos d'água foi definida pela Resolução CONAMA n 357/2005, onde são estabelecidas as diretrizes para a classificação dos corpos hídricos em classes de uso, bem como os padrões de qualidade e para o lançamento de efluentes (BRASIL, 2005).

Por sua vez, a Diretiva Quadro da Água - DQA, implementada no início do século XXI como uma nova estratégia de planejamento e gestão dos recursos hídricos na União Europeia, tem como base uma abordagem ecológica e possui como objetivo principal alcançar o bom estado ecológico para os corpos hídricos dos EstadosMembros da UE (SARAIVA, 2010).

Neste sentido, o objetivo central deste artigo é traçar paralelos de análise de enquadramento das águas para as diretivas de qualidade aplicadas no Brasil e na União Europeia, com a perspectiva de uso agregador do enquadramento europeu em sistemas de abastecimento de água humano no Brasil.

\section{A busca da real qualidade das águas}

A medição da qualidade ambiental das águas superficiais dos continentes requer diretrizes para geração e análise de dados acuradas. Uma das ferramentas muito útil é o monitoramento da qualidade da água de um determinado ambiente, tanto ao longo do tempo como também espacialmente. $O$ desenho amostral repetido nessas duas séries permite o acompanhamento das condições ambientais e biológicas, e a partir das informações obtidas, realizar o enquadramento das águas de acordo com as diretivas utilizadas.

A qualidade de um corpo hídrico pode ser representada por meio da análise dos diversos elementos presentes na água, esses, por sua vez, demonstram as características físicas, químicas e biológicas do ambiente aquático. Além disso, a qualidade de água é condicionada por variáveis naturais ligadas ao regime de chuvas, escoamento superficial, geologia e cobertura vegetal, e por impactos antrópicos, como o lançamento de efluentes, manejo dos solos, entre outros.

Dessa forma, o monitoramento ambiental é de grande importância para o conhecimento das tendências de evolução da qualidade das águas, especialmente a longo prazo, pois permite a quantificação das variáveis físicas, químicas e biológicas, e desse modo, viabiliza o diagnóstico ambiental daquela água.

Esse diagnóstico propicia a avaliação dos ambientes aquáticos em resposta aos impactos antrópicos na área de drenagem ou de influência, em termos espaciais e temporais. Contudo, os programas de monitoramento margeiam-se a apresentar uma grande quantidade de dados sem, no entanto, sistematizá-los de 
maneira que possam orientar planos de gestão da qualidade da água e de gerenciamento dos recursos hídricos (CUNHA \& CALIJURI, 2010).

Protocolos de avaliação rápida de rios são amplamente utilizados em monitoramentos de qualidade de água, e desde 1980 (EPA, 1987) operam como um método viável e de fácil execução. Padovesi-Fonseca et al., (2010) obtiveram resultados bem demarcados na sub-bacia do ribeirão Mestre d'Armas, Distrito Federal, quando comparados entre áreas protegida, de transição e urbana. As diferenças foram decorrentes da presença e tipo de impacto antropogênico. Neste sentido, este método proporciona medidas comparativas em rotinas de gerenciamento ambiental e de recursos hídricos de uma região.

Muitos pesquisadores têm utilizado técnicas de aprimoramento nas redes de monitoramento, como a utilização de ferramentas de estatística multivariada para diminuir os custos referentes à busca de dados realizados em campo. De acordo com NONATO et al., (2007), os métodos estatísticos possibilitam otimizar a rede de amostragem proposta, a frequência de amostragem e o número de parâmetros analisados.

Outras iniciativas foram inseridas na questão de aperfeiçoamento do enquadramento de corpos hídricos com metas progressivas. Nessa perspectiva, tem-se a proposta de estabelecimento de uma relação entre vazão de entrada no corpo d'água e concentrações de variáveis sensíveis às alterações de condições ambientais. Como exemplo, Brites (2010) propôs simulações de qualidade de água entre vazões e a demanda bioquímica de oxigênio (DBO) como um sensor de monitoramento viável e preciso de qualidade de água. Segundo a autora, essa ferramenta se constituiu uma alternativa viável para o enquadramento das águas, além de subsidiar as medidas necessárias para sua despoluição.

Dificuldades na gestão da qualidade dos recursos hídricos são originadas de deficiências em termos de monitoramento e fiscalização e, em consequência, corpos hídricos já enquadrados podem ficar em desacordo com a classe de qualidade designada, como discutido por Bradão et al., (2006) e Diniz et al., (2006).

Importante destacar que a ausência de registros históricos, principalmente em pequenas bacias, a imaturidade das políticas públicas e a variação nas taxas de erosão em uma mesma localidade são problemas que podem dificultar os estudos relacionados à degradação ambiental gerada pela ocupação e uso do solo desordenados no Brasil (COUCEIRO; PADOVESI-FONSECA, 2009).

$\mathrm{O}$ uso de monitoramento em estudos de impactos ambientais tem a premissa de realizar um diagnóstico desencadeador na avaliação da qualidade ambiental e de suas águas. Inclui, para esse propósito, necessidades e medidas mitigadoras ou compensatórias dos impactos em um ambiente e a partir disso, proposição de melhores formas de gerenciamento desses ambientes afetados, com a finalidade de garantir o uso sustentável dos recursos naturais. Em virtude disso, os cientistas têm sido pressionados a desenvolver métodos de avaliação que sejam eficientes, tanto em nível da própria avaliação, quanto auxiliares nas tomadas de decisões nos processos de gerenciamento ambiental (RODRIGUES et al., 2008b), e o efetivo enquadramento de suas águas. 
O monitoramento da qualidade da água é essencial para indicar tendências e áreas prioritárias para o controle da poluição hídrica, como enfatiza a Agência Nacional de Águas (ANA), autarquia federal responsável pela implementação da gestão dos recursos hídricos brasileiros. Destaca que o monitoramento propicia a efetividade destas ações e instrumentos de gestão, como o enquadramento de corpos hídricos em classes de qualidade (ANA, 2019).

Diante das dificuldades econômicas e de logística existentes na maioria dos municípios do Brasil, é imperativo a busca de alternativas para o monitoramento e avaliação da qualidade de água a serem inseridos na aplicação das diretivas. RODRIGUES et al., (2008a) ressaltam a importância do uso de métodos de diagnóstico e de avaliação com menores custos e de fácil aplicação, por estes gerarem respostas mais rápidas para serem utilizadas em gestões ambientais e hídricas.

Por fim, é salutar que os gestores, junto com o governo brasileiro, aumentem a rede de monitoramento com a finalidade de subsidiar a falta de informações e, desta forma, concentrar esforços em áreas críticas, procurando preencher as lacunas técnicas fundamentais para o planejamento e a gestão dos recursos hídricos.

\section{A qualidade e seus quadros em águas doces}

A água é um bem natural e essencial para a existência e permanência da vida, e com o desenvolvimento das sociedades humanas, é utilizada para diversos fins, e assim considerada como um dos principais recursos ambientais. Com vistas a garantir atendimento aos seus diversos usos e o acesso a todos, as nações aplicam instrumentos de gestão de suas águas para delinear as atividades humanas de forma a garantir a preservação e o modo contínuo da qualidade das águas.

$\mathrm{O}$ enquadramento dos corpos d'água é um dos instrumentos aplicados para o gerenciamento dos recursos hídricos. No Brasil esta diretriz rege de acordo com a Resolução do Conselho Nacional do Meio Ambiente (CONAMA) n 357 (BRASIL, 2005), que estabelece classes de qualidade hídrica em função dos usos preponderantes da água. Com isso, visa assegurar qualidade das águas compatíveis com os seus usos mais exigentes e, por consequência, diminuir os custos de combate à sua deterioração.

O enquadramento é obtido a partir de uma série de parâmetros de qualidade de água e são estabelecidas cinco classes. Da Classe Especial, que representa os usos mais exigentes e de elevada qualidade da água, como a proteção e a preservação da vida aquática, até a Classe 4, que expressa os usos menos exigentes, como a navegação e a harmonia paisagística (Figura 1).

O uso da água para abastecimento humano requer tratamento específico de acordo com o enquadramento (Figura 1). Em águas classificadas especiais, podem ser consumidas após desinfecção. Para as classes de 1 a 3, por sua vez, podem ser consumidas após tratamento da água, e de forma progressiva de acordo com o enquadramento, desde tratamentos mais simplificados até os mais avançados. 
Figura 1: Classes de enquadramento e níveis de exigência de usos a que se destinam as águas doces.

\section{Classe de enquadramento dos corpos d'água}

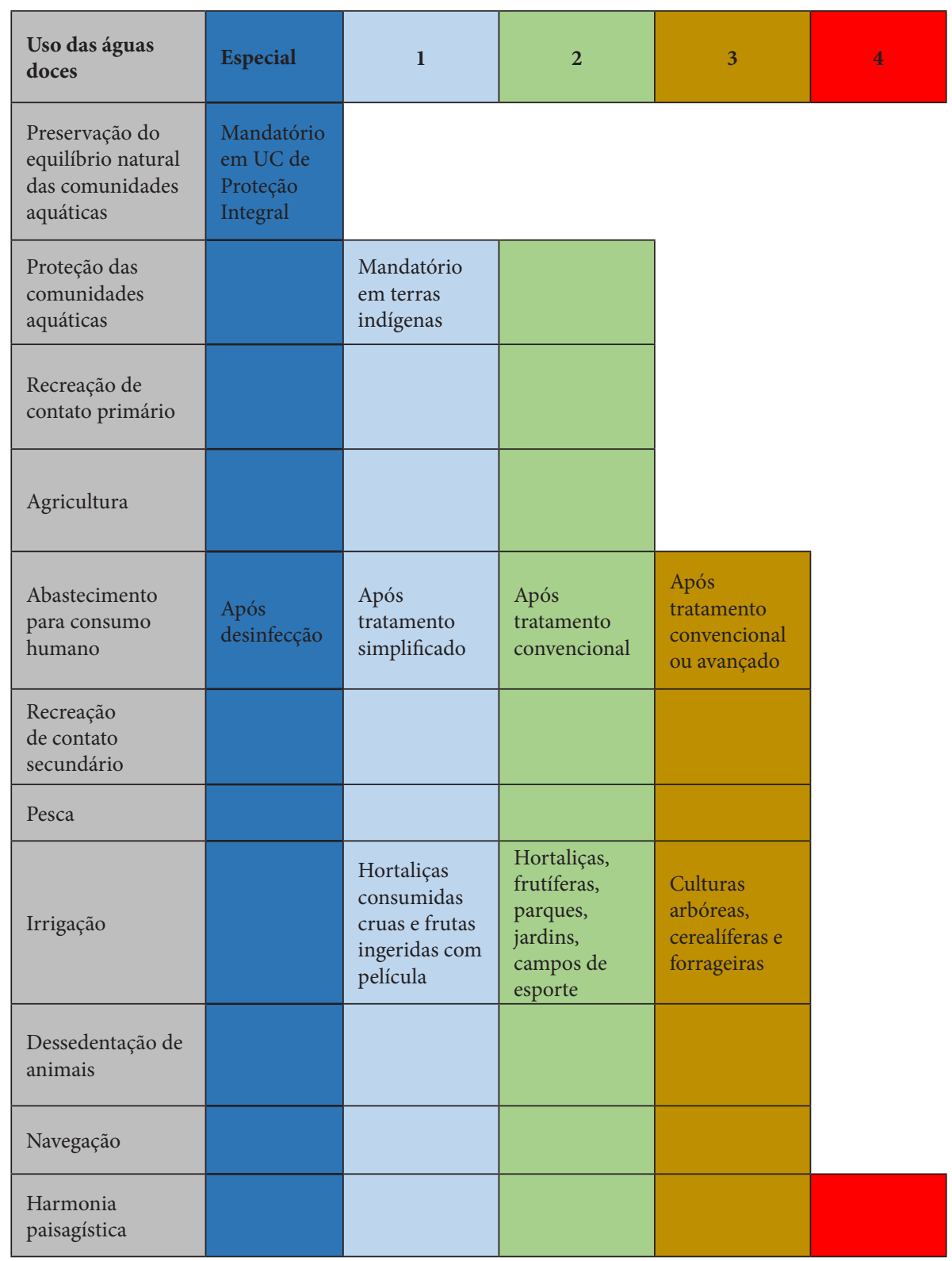

Fonte: Adaptado de SigRH (2019). 
A Resolução no 91 de 05 de novembro de 2005, estabelecida pelo Conselho Nacional de Recursos Hídricos, regulamenta os procedimentos gerais para o enquadramento dos corpos de água no Brasil. Essa resolução determina que o enquadramento deve ser desenvolvido de preferência no decorrer da elaboração do Plano de Recursos Hídricos da bacia hidrográfica em questão. Deve também conter um programa para efetivação dos objetivos, metas, planos de investimentos e compromissos (BRASIL, 2008) (Figura 2).

Figura 2: Diagrama do processo de enquadramento segundo a Resolução no 91 de 05 de novembro de 2005.

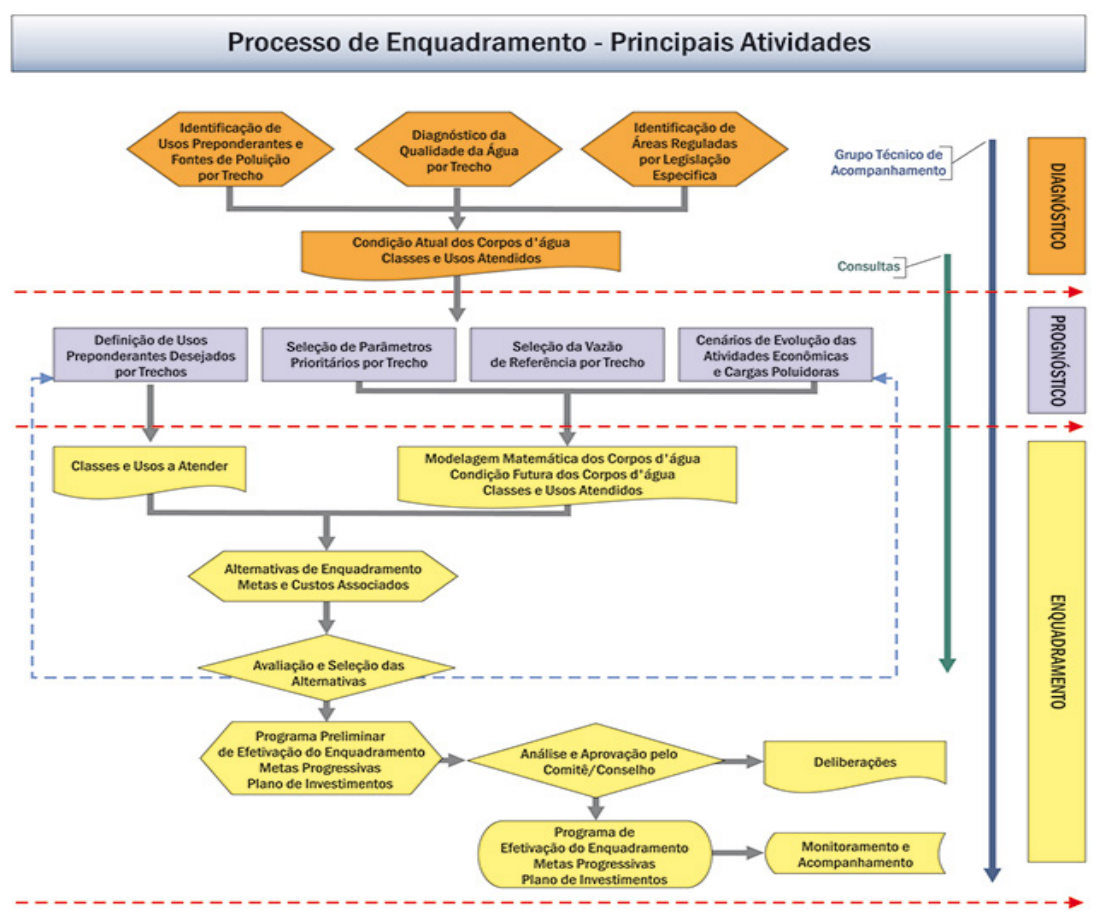

Fonte: SigRH (2019).

Machado et al., (2019) comentam que há uma certa arbitrariedade na elaboração de diagnósticos, na definição dos parâmetros-base e na configuração de cenários para obtenção do enquadramento de corpos d'água. Este argumento serve de alerta por ser um dos instrumentos de gestão hídrica diretamente ligado com a questão da qualidade e quantidade da água, sendo de grande importância para a concessão de outorgas e licenças ambientais.

Mesmo conhecendo os benefícios do enquadramento dos corpos hídricos, a sua implementação é considerada um desafio para o sistema de gerenciamento de 
recursos hídricos no Brasil, visto que são poucas as experiências de aplicação desse instrumento de gestão. A falta de conhecimento sobre o instrumento, dificuldades metodológicas para sua aplicação e insuficiência de ações de gestão e de recursos fundamentais para sua efetivação são alguns dos entraves relacionados (MACHADO op. cit., 2019 e referências).

Cabe salientar que o enquadramento de um corpo hídrico não indica, necessariamente, a qualidade atual, mas sim uma possível estratégia de planejamento para atendimento às metas de médio e longo prazos estabelecidas nas diretrizes de gestores de tomada de decisão de uma determinada região ou bacia hidrográfica. Estabelecer a qualidade de água pretendida supõe uma avaliação da condição atual do corpo hídrico - o rio que temos - e a verificação com as partes interessadas da qualidade desejada para aquele curso d'água - o rio que queremos. Além disso, é necessário definir as metas com todos envolvidos, considerando os aspectos técnicos e econômicos para alcançá-las - o rio que podemos ter (SILVA, 2017). Cardoso-Silva et al., (2015) ratificam esses aspectos e argumenta que, no caso dos padrões de qualidade estabelecidos não sejam atendidos, as classes nas quais os corpos hídricos são enquadrados devem ser entendidas como metas a serem alcançadas.

Otomo et al., (2015) realçam aspectos falhos na efetivação do enquadramento devido a flexibilidade na adequação das metas atingidas. Em especial, elencam a falta de estabelecimento de prazos para atingir as metas estabelecidas pela Resolução Conama e, dessa forma, muitos corpos hídricos tendem a permanecer degradados. Podem ser acrescentados a não efetivação do enquadramento, a ausência de planos de gestão de bacias hidrográficas, de planos sem consolidação, que não apresentam ações consolidadas para que o enquadramento seja atingido, além da falta de conhecimento da população a respeito do instrumento, bem como de um sistema de monitoramento abrangente dos corpos hídricos (FOLETO, 2018).

As diretrizes da gestão de recursos hídricos no Brasil ainda devem ser contextualizadas para posições que discriminem com clareza as classes das águas e seu enquadramento. Os padrões de categorias devem refletir particularidades regionais, além de inserir, como prioridade, a proteção dos ecossistemas aquáticos e seus mananciais, como salientado por diversos pesquisadores (YASSUDA, 1993; CARDOSOSILVA et al., 2015; OTOMO et al., 2015).

\section{Pares e alelos das diretivas no enquadramento Brasil e Europa}

As políticas de água adotadas por governos, tanto do Brasil quanto da União Europeia, são detalhadas em diretrizes e programas, em função da natureza de bem comum da água e dos múltiplos usuários e interesses envolvidos. Exercem grande importância sobre a qualidade e quantidade dos recursos hídricos (CE, 2000; BRASIL, 2005).

A Resolução Conama no 357/2005, que se refere à classificação dos corpos hídricos quanto ao uso no Brasil, possui um ordenamento de gestão de recursos hídricos bem delineados e com uma série de parâmetros de qualidade de água. Entretanto, 
a Diretiva Quadro da Água Europeia (DQAE) apresenta outros parâmetros, como a hidromorfologia e a biota aquática dos corpos d'água e, com isso, uma ampliação na perspectiva de obtenção da real classificação da água (SOBRAL et al., 2008).

O uso da biota aquática na classificação das águas e em programas de monitoramento tem pretensão de acessar a estrutura e função das comunidades, e com isso avaliar com mais precisão sua qualidade. $\mathrm{O}$ uso de organismos aquáticos, como o zooplâncton, como indicadores de qualidade de água se mostrou bem promissor para ambientes aquáticos sujeitos à poluição. Em estudo realizado no reservatório Paranoá situado no Distrito Federal, o zooplâncton foi a comunidade biológica escolhida como sensor na proposta da DQAE. A inclusão deste grupo biológico como elemento de qualidade produziu dois diferentes cenários referentes ao nível de poluição. No período mais poluído dominaram espécies pequenas e detritívoras; ao passo que no período em que o reservatório ficou menos poluído as espécies maiores e filtradoras foram dominantes (PADOVESI-FONSECA, 2020).

Vale salientar que o zooplâncton não foi inserido na implementação da DQA na Europa, apesar de ser considerado um componente chave para bioindicação (CARONI \& IRVINE, 2010; DAVIDSON et al., 2011; EJSMONT-KARABIN, 2012). A inclusão deste grupo biológico, bem como de sua avaliação em águas de abastecimento humano no Brasil, configuram elementos essenciais na gestão e enquadramento das águas.

A Diretiva Quadro da Água (DQA) da União Europeia aparece como uma alternativa promissora no gerenciamento dos recursos hídricos brasileiro, pois possui como objetivo alcançar o bom estado ecológico do corpo d'água (EC, 2012), diferentemente do modelo de gestão de recursos hídricos do Brasil, que tem como foco da gestão o uso que se faz da água (BRASIL 2005). Com isso, a inclusão da DQAE no Brasil, e em especial, em sistemas de abastecimento humano, fornece subsídios para consolidar a proteção dos meios hídricos à comunidade, pois estabelece em suas diretrizes a promoção do uso sustentável da água, além da proteção de ecossistemas aquáticos e seus mananciais.

Ademais da abordagem ecológica e de efetiva proteção de mananciais, a diretiva quadro da água na Europa apresenta um planejamento integrado entre os tomadores de decisão e a participação da comunidade, por meio de instrumentos legais e divulgação participativa comunitária (APAMBIENTE, 2020). Neste sentido, a participação da comunidade representa um dos pilares para a implementação da DQA na União Europeia. Junto com diagnóstico e prognóstico, estabelece um marco comunitário nas diretrizes para gestão de recursos hídricos e seu enquadramento (RABELO, 2012).

A estrutura da DQAE é bastante complexa e apresenta interfaces com o enquadramento das águas. Os objetivos serão cumpridos por meio de programas de medidas (Art. $11^{\circ}$ ) que por sua vez, devem ser incluídos nos Planos de Gestão de Bacias Hidrográficas (Art. 13º) (Figura 3). 
Figura 3: Estrutura organizacional da Diretiva Quadro da Água.

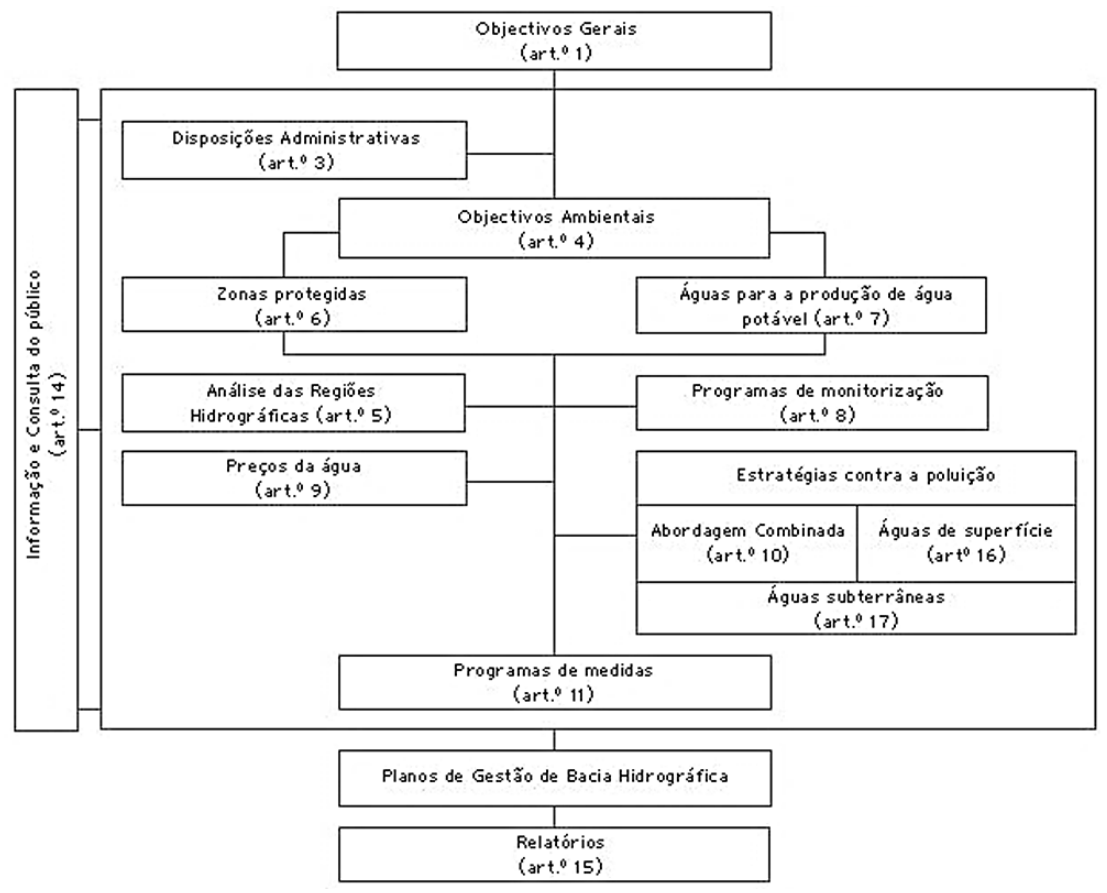

Fonte: APAMBIENTE (2020).

Uma das características peculiares da DQAE, em contraste à Política Nacional de Recursos Hídricos (PNRH) do Brasil, consiste em estabelecer metas progressivas em determinadas datas para garantir um acompanhamento mais efetivo do processo de avaliação e resposta. Também define programas de medidas para atingir os objetivos de qualidade da água do ecossistema de referência, de forma integrada dos recursos hídricos no âmbito das bacias hidrográficas, independentemente dos limites territoriais da região avaliada (SOBRAL et al., 2008).

Outra marca diferente da Diretiva-Quadro da União Europeia é designar o conceito de qualidade ecológica das massas d'água. Este conceito está vinculado às exigências dos setores de comunidades europeias, e com viés sustentável para garantir as necessidades humanas futuras. Desse modo, como argumenta CORREIA (2005), afasta-se dos conceitos tradicionais baseados somente em parâmetros de qualidade de água, como visto na concepção da legislação brasileira (BRASIL, 2005).

A implementação da Diretiva-Quadro representa um avanço na gestão dos recursos hídricos, pois agrega todos os estados-membros da União Europeia. Com isso, exige uma ação coerente e cooperação nos diferentes níveis da sociedade, do local, do regional, do comunitário em comum com os estados-membros (RABELO, 2012). Esta 
mudança de paradigma efetivou a cobrança da sociedade bem como de pesquisadores e especialistas para a implementação e desenvolvimento das diretrizes no âmbito da União Europeia (SARAIVA, 2010). De acordo com as diretrizes da DQA Europeia, a Tabela 1 apresenta as definições dos diferentes estados de qualidade hídrica, bem como o que representa o bom estado, para as águas continentais.

Tabela 1: Classificação do estado dos recursos hídricos de acordo com a Diretiva 2000/60/CE. Diretriz do Parlamento Europeu e do Conselho n. ${ }^{\circ}$ 2000/60/CE, de 23 de outubro de 2000 .

\begin{tabular}{|c|c|c|}
\hline Estado & Definição & O bom estado \\
\hline Químico & $\begin{array}{l}\text { Para os recursos hídricos de superfície: } \\
\text { Presença de substâncias químicas que em con- } \\
\text { dições naturais, não estariam presentes, e que } \\
\text { são susceptíveis de causar danos significativos } \\
\text { para saúde humana e para flora e fauna, pelas } \\
\text { suas características de persistência, toxicida- } \\
\text { de, bioacumulação (substâncias perigosas - } \\
\text { Diretiva 76/464/CEE) } \\
\text { Os critérios de seleção das substâncias } \\
\text { prioritárias a serem eliminadas baseiam-se na } \\
\text { combinação entre o grau de periculosidade } \\
\text { das próprias substâncias e a exposição am- } \\
\text { biental a essas mesmas substâncias. Diretiva- } \\
\text {-Quadro estabelece estratégias para a redução } \\
\text { ou eliminação progressiva das descargas, } \\
\text { emissões e perdas dessas substâncias, para as } \\
\text { águas superficiais. }\end{array}$ & $\begin{array}{c}\text { Águas de superfície: } \\
\text { Corresponde ou à ausência } \\
\text { dessas substâncias nas águas, ou } \\
\text { a presença com concentrações } \\
\text { inferiores às normas } \\
\text { de qualidade estabelecidas a } \\
\text { nível comunitário. } \\
\text { Águas subterrâneas: } \\
\text { Concentrações de poluentes não } \\
\text { apresentem salinidade ou outro } \\
\text { poluente que provoquem danos } \\
\text { significativos aos ecossistemas } \\
\text { terrestres que dependam desses } \\
\text { recursos hídricos. }\end{array}$ \\
\hline Ecológico & $\begin{array}{l}\text { Relaciona-se à qualidade estrutural e funcional } \\
\text { dos ecossistemas aquáticos associados às águas } \\
\text { de superfície. Este conceito, cuja definição é es- } \\
\text { pecificada os diferentes tipos de água, engloba } \\
\text { diversos parâmetros relativos à natureza físico- } \\
\text {-química da água, às características hidrodinâ- } \\
\text { micas e à estrutura física dos meios hídricos. } \\
\text { São definidos } 3 \text { grupos de parâmetros: bióticos, } \\
\text { hidromorfológicos e físico-químicos. } \\
\text { O “estado ecológico" é expresso relativamente } \\
\text { a uma "situação de referência”, que é a situação } \\
\text { dos ecossistemas aquáticos na ausência de } \\
\text { qualquer influência antrópica significativa, ou } \\
\text { seja, o fim de toda a influência antrópica sobre } \\
\text { os recursos hídricos, com todas as medidas } \\
\text { para restaurar as condições hidromorfológicas, } \\
\text { físico-químicas e bióticas originais, aplicadas. }\end{array}$ & $\begin{array}{l}\text { Águas de superfície: } \\
\text { Mesmo que sujeitas à influência } \\
\text { significativa das atividades } \\
\text { humanas, que se traduz por um } \\
\text { desvio relativamente à “situação } \\
\text { de referência”, constitui, ainda } \\
\text { assim, um ecossistema rico, } \\
\text { diversificado e sustentável. }\end{array}$ \\
\hline
\end{tabular}




\begin{tabular}{|c|c|c|}
\hline Quantitativo & $\begin{array}{c}\text { É o estado hidrodinâmico dos recursos } \\
\text { hídricos subterrâneos sujeito a extrações e } \\
\text { a descargas de água, diretas e indiretas, e a } \\
\text { alterações da recarga natural devido às ações } \\
\text { antrópicas. }\end{array}$ & $\begin{array}{c}\text { Águas subterrâneas: } \\
\text { Quando no sistema aquífero o } \\
\text { balanço entre as extrações e as } \\
\text { descargas de água, por um lado, } \\
\text { e as alterações da recarga natural, } \\
\text { por outro, é sustentável a longo } \\
\text { prazo, e não provoca à degrada- } \\
\text { ção da qualidade ecológica das } \\
\text { águas de superfície hidraulica- } \\
\text { mente conectadas com o sistema } \\
\text { aquífero, nem afetam a qualidade } \\
\text { dos ecossistemas terrestres e das } \\
\text { zonas úmidas associadas. }\end{array}$ \\
\hline $\begin{array}{l}\text { Potencial } \\
\text { ecológico }\end{array}$ & $\begin{array}{l}\text { O conceito de "estado ecológico" só é aplicá- } \\
\text { vel aos recursos hídricos de superfície cujas } \\
\text { condições hidromorfológicas sejam aproxi- } \\
\text { madamente idênticas às que corresponderiam } \\
\text { às condições naturais respectivas. A atividade } \\
\text { humana apenas provoca alterações significa- } \\
\text { tivas nas condições físico-químicas e bióticas } \\
\text { desses recursos hídricos, e com a cessação de } \\
\text { todas as ações antrópicas, essas águas retorna- } \\
\text { riam às condições naturais que correspondem } \\
\text { à "situação de referência". } \\
\text { Os recursos hídricos cujas características } \\
\text { hidromorfológicas tenham sido alterados } \\
\text { pelas atividades humanas de tal forma que } \\
\text { tenham resultado numa mudança substancial } \\
\text { relativamente ao tipo de recurso hídrico de } \\
\text { referência, como é o caso de canais e dos } \\
\text { portos, designados como recursos hídricos } \\
\text { artificiais ou fortemente modificados, } \\
\text { o conceito de "bom estado ecológico" é } \\
\text { substituído pelo de "bom potencial ecológico". }\end{array}$ & $\begin{array}{c}\text { Águas superficiais: } \\
\text { Os recursos hídricos podem ser } \\
\text { designados como artificiais ou } \\
\text { fortemente modificados, quando } \\
\text { não seja possível modificar as } \\
\text { condições hidromorfológicas } \\
\text { necessárias para a reconstituição } \\
\text { do "bom estado ecológico", por } \\
\text { serem modificações tecnica- } \\
\text { mente ou economicamente } \\
\text { inviáveis ou quando as modi- } \\
\text { ficações exigíveis possam ser } \\
\text { adversas para o ambiente ou } \\
\text { quando avaliadas num contexto } \\
\text { socioeconômico em função } \\
\text { do uso múltiplo das águas. }\end{array}$ \\
\hline
\end{tabular}

Fonte: Sobral et al., 2008.

Em resumo, três aspectos podem ser destacados para análise da inserção da Diretiva-Quadro da UE em sistemas de abastecimento humano no Brasil. O primeiro aspecto a ser destacado é a inclusão de parâmetros hidromorfológicos dos corpos hídricos bem como de sua biota aquática prevista na DQAE. As dimensões morfométricas de rios, lagos e reservatórios, por exemplo, bem como de seus fluxos e vazões, exercem influência na qualidade de suas águas, como foi evidenciado em estudos de avaliação rápida de rios (PADOVESI-FONSECA et al., 2010). A inclusão da biota aquática para avaliação da qualidade de água foi evidenciada na seção 4 deste artigo. 
O segundo item se refere à necessidade de estimular a participação da comunidade na garantia e visibilidade da sociedade de forma democrática. A sociedade participa em tomadas de decisão e mecanismos de informação e comunicação, e consequente na gestão participativa da política de recursos hídricos (RABELO, 2012). A legislação brasileira é bastante genérica nesse aspecto, mais centrada nas necessidades de ordem técnica do que de mobilização social.

O terceiro item integra a estrutura organizacional da DQA de forma mais ampla, em estados-membros. Talvez este não seja mais adequado à realidade brasileira. Os comitês de bacia hidrográfica têm independência nas decisões relativas ao gerenciamento de suas bacias.

Entretanto, ao mesmo tempo que as diretrizes pautadas pela DQA na União Europeia possibilitem ampliar a visibilidade e o interesse da participação da sociedade, de outro lado pode inibir iniciativas originais ou adequadas à realidade de cada lugar, ou mesmo ao gerenciamento de determinada bacia hidrográfica.

\section{Conclusões}

Ficou notório que o gerenciamento adequado de recursos hídricos é bastante complexo, e engloba desenhos de análise por instrumentos técnicos viáveis e complementares, e que seguem diretrizes de legislação ambiental na medida de produção de cenários mais consolidados para o seu enquadramento.

Apesar da legislação brasileira sobre recursos hídricos apresentar grande avanço com o passar dos anos, constata-se que ainda é precária a situação em que se encontram muitos corpos hídricos no Brasil. A Política das Águas apresenta uma série de medidas promissoras, que provavelmente alcançarão resultados eficazes na preservação das águas, mas muito ainda pode ser feito no sentido de aprimorar a gestão dos recursos hídricos no país. 


\section{Referências}

AGÊNCIA NACIONAL DE ÁGUAS - ANA. Conjuntura dos Recursos Hídricos no Brasil 2019: informe anual / Agência Nacional de Águas. Brasília: ANA, 100p. 2019.

APAMBIENTE. Sítio Oficial da Directiva Quadro da Água. 2020. Disponível em: http://apambiente.pt/dqa/index.html. Acesso em: 03 jan. 2020.

BRANDÃO, J. L. B.; MALTA, L. R.; MASINI, L. S.; STUART, L. C.; PORTO, M. F.A. Experiências nacional e internacional sobre o enquadramento dos cursos d'água. In: Simpósio de Recursos Hídricos do Sul-Sudeste, 1., 2006, Curitiba. Anais [...]. Curitiba: ABRH, 2006.

BRASIL. (1997) Lei $\boldsymbol{n}^{\boldsymbol{0}}$ 9.433, de 8 de janeiro de 1997. Institui a Política Nacional de Recursos Hídricos e cria o Sistema Nacional de Gerenciamento de Recursos Hídricos. Brasília (DF). Diário Oficial da República Federativa do Brasil. Brasília, DF. 1997.

BRASIL. (2005) Conselho Nacional do Meio Ambiente. Resolução $n^{\circ} 357$ de 17 de março de 2005. Dispõe sobre a classificação dos corpos de água e diretrizes ambientais para o seu enquadramento, bem como estabelece as condições e padrões de lançamento de efluentes, e dá outras providências. Diário Oficial da República Federativa do Brasil. Brasília, DF. 2005.

BRASIL. (2008) Conselho Nacional de Recursos Hídricos. Resolução $\boldsymbol{n}^{\mathbf{o}} \mathbf{9 1}$, de 5 de novembro de 2008. Dispõe sobre os procedimentos gerais para o enquadramento dos corpos d'água superficiais e subterrâneos. Diário Oficial da República Federativa do Brasil. Brasília, DF. 2008.

BRITES, A. P. Z. Enquadramento dos corpos de água através de metas progressivas: probabilidade de ocorrência e custos de despoluição hídrica. 2010. 205 p. Tese (Doutorado) - Escola Politécnica da Universidade de São Paulo. Departamento de Engenharia Hidráulica e Sanitária, Universidade de São Paulo, 2010.

CARDOSO-SILVA, S.; FERREIRA, T.; POMPÊO, M. L. M. Diretiva Quadro d'Água: uma revisão crítica e a possibilidade de aplicação ao Brasil. Revista Ambiente \& Sociedade, v. XVI, n. 1, p. 39-58, 2013.

CARDOSO-SILVA, S.; MARIANI, C. F.; POMPÊO, M. Análise crítica da Resolução CONAMA no 357 à luz da Diretiva Quadro da Água da União Europeia: Estudo de caso (Represa do Guarapiranga - São Paulo, Brasil). In: POMPÊO, M. et al. Ecologia de reservatórios e interfaces. São Paulo: Instituto de Biociências da Universidade de São Paulo, p. 367-375, 2015.

CARONI, R.; IRVINE, K. The potential of zooplankton communities for ecological assessment of lakes: redudant concept or political oversight?. Biology and Environment Proceedings of the Royal Irish Academy 110(1): 35-53, 2010. 
CE (2000). Directiva 2000/60/CE do Parlamento Europeu e do Conselho de 23 de outubro de 2000 que Estabelece um Quadro de Acção Comunitária no Domínio da Política da Água. Jornal Oficial das Comunidades Europeias, 22.12.2000, Bruxelas.

CORREIA, F. N. Algumas reflexões sobre os mecanismos de Gestão de Recursos Hídricos e a experiência da União Europeia. Rega, vol. 2, n. 2, p. 5-16, 2005.

COUCEIRO, S. M.; PADOVESI-FONSECA, C. Sedimentos reduzem biodiversidade. Ciência Hoje, vol. 262, p. 60-63, 2009.

CUNHA, D. G. F.; CALIJURI, M. C. Análise probabilística de ocorrência de incompatibilidade da qualidade da água com o enquadramento legal de sistemas aquáticos - estudo de caso do rio Pariquera-Açu (SP). Revista Engenharia Sanitária e Ambiental, vol. 15, n. 4, p. 337-346, 2010.

DAVIDSON, T.; BENNION, A. H.; JEPPESEN, E.; CLARKE, G. H.; SAYER, C. et al. The role of cladocerans in tracking long-term change in shallow lake trophic status. Hydrobiologia 676: 299-315, 2011.

DINIZ, L. T.; YAZAKI, L. F. O.; JUNIOR, J. M. M.; PORTO, M. F. A. O enquadramento de cursos d'água na legislação brasileira. In: Simpósio de Recursos Hídricos do SulSudeste, 1., 2006, Curitiba. Anais [...]. Curitiba: ABRH, 2006.

EC-European Commission. Report from the Commission to the European Parlament an the Council on the Implementation of the Water Framework Directive (2000/60/ EC): River Basin Management Plans. Brussels. 15 p. 2012.

EJSMONT-KARABIN, J. The usefulness of zooplankton as lake ecosystem indicators: rotifer trophic index. Polish Journal of Ecology 60: 339-350, 2012.

FOLETO, E. M. O Contexto dos Instrumentos de Gerenciamento dos Recursos Hídricos no Brasil. Revista Eletrônica do Curso de Geografia. Jataí, GO, v. 1, n. 30, p. 39-59, 2018.

EPA - UNITED STATES ENVIRONMENTAL PROTECTION AGENCY. Biological criteria for protection of aquatic life. Columbus: Division of Water Quality Monitoring and Assessment, 120 p., 1987.

MACHADO, E. S.; KNAPIK, H. G.; BITENCOURT, C. C. A. Considerações sobre o processo de enquadramento de corpos de água. Revista Engenharia Sanitária e Ambiental, vol. 24, n. 2, p. 261-269, 2019.

NONATO, E. A.; VIOLA, Z. G. G.; ALMEIDA, K. C. B.; SCHOR, H. H. R. Tratamento estatístico dos parâmetros da qualidade das águas da bacia do Alto Curso do Rio das Velhas. Química Nova, vol. 30, n. 4, p. 797-804, 2007. 
OTOMO, J. I.; CARDOSO-SILVA, S.; SANTOS, W. D.; JARDIM, E. A. M.; POMPÊO, M. Avaliação de políticas para preservação e recuperação de mananciais de abastecimento público da região metropolitana de São Paulo. In: POMPÊO, M. et al. Ecologia de reservatórios e interfaces. São Paulo: Instituto de Biociências da Universidade de São Paulo, 2015, p. 376-395.

PADOVESI-FONSECA, C.; CORRÊA, A. C. G.; LEITE, G. F. M.; JOVELI, J. C.; COSTA, L. S.; PEREIRA, S. T. Diagnóstico da sub-bacia do ribeirão Mestre d'Armas por meio de dois métodos de avaliação ambiental rápida, Distrito Federal, Brasil Central. Ambi-Agua, vol. 5, n. 1, p. 43-56, 2010.

PADOVESI-FONSECA. C. Potential use of zooplankton as ecological quality indicator according to Water Framework Directive (WFD) in Central Brazilian Reservoir. Oceanogr Fish Open Access J, vol. 11, n. 3, 2020.

RABELO, D. C. Informação e comunicação na gestão participativa: uma análise a partir das políticas de recursos hídricos do Brasil e da Europa. Revista Emancipação, vol. 2, n. 2, p. 253-264, 2012.

RODRIGUES. A. S. L.; CASTRO, P. T. A. Adaptation of a rapid assessment protocol for rivers on rocky meadows. Acta Limnologica Brasiliensis, Botucatu, vol. 20, n. 4, p. 291-303, 2008a.

RODRIGUES, A. S. L.; CASTRO, P. T. A. Protocolos de avaliação rápida: instrumentos complementares no monitoramento dos recursos hídricos. Revista Brasileira de Recursos Hídricos, Porto Alegre, vol. 13, n. 1, p. 161-170, $2008 \mathrm{~b}$.

SARAIVA, F. A. S. O potencial ecológico no âmbito da Directiva-Quadro da Água Conceitos e metodologias de definição. 2010. 111p. Dissertação (mestrado). Faculdade de Ciências e Tecnologia da Universidade Nova de Lisboa. Departamento de Ciências e Engenharia do Ambiente, Universidade Nova de Lisboa, Lisboa, 2010.

SIGRH - Secretaria de Saneamento e Recursos Hídricos. Enquadramento dos corpos de água em classes segundo os usos preponderantes: correlação com plano de bacia, sistema de informação e monitoramento. Coordenadoria de Recursos Hídricos - CRHi: São Paulo. Disponível em: http://www.sigrh.sp.gov.br/arquivos/ enquadramento/PBH_Enquad_p_CBHs_nov14.pdf. Acesso em: $12 \mathrm{dez} .2019$.

SILVA, M. T. L. Aplicação do índice de conformidade ao enquadramento (ICE) de cursos d’água. 2017.201p. Dissertação (Mestrado). Engenharia Sanitária, Universidade Federal de Minas Gerais, Belo Horizonte, 2017.

SOBRAL, M. C.; GUNKEL, G.; BARROS, A. M.; PAES, R.; FIGUEIREDO, R. C. Classificação de Corpos d'água segundo a Diretiva Quadro da Água da União Europeia - 2000/60/CE. Revista Brasileira de Ciências Ambientais, v. 11, p. 30-39, 2008.

YASSUDA, E. R. Gestão de recursos hídricos: fundamentos e aspectos institucionais. Revista Administração Pública. Rio de Janeiro, v. 27, n.2, p.5-18, 1993. 
